\title{
Urban flood mitigation: sustainable options
}

\author{
D. Serre ${ }^{1}$, B. Barroca ${ }^{2} \&$ Y. Diab ${ }^{1,2}$ \\ ${ }^{1}$ Université Paris-Est - Ecole des Ingénieurs de la Ville de Paris, France \\ ${ }^{2}$ Université Paris-Est - Laboratoire Eau Environnement et Systèmes \\ Urbains, France
}

\begin{abstract}
Cities have started to anticipate the effects of global warming dealing with flood management. Indeed, it seems that this last decade, flood risk has increased and cities are facing on the one hand more frequent hazards, and on the other hand different types of flooding: fluvial, coastal, estuarial and pluvial. Most cities have to manage at least two of these flooding types. At the same time, flood risk management practices have changed step-by-step. Indeed, despite efforts made to maintain the flood defense assets well, we often observe failures leading to finally increase flood risk in protected areas during major flood events. Moreover, flood forecasting models, although they benefit from continuous improvements, remain partly inaccurate due to uncertainties populated all along data calculation processes. This means cities cannot continue to manage flood risk only by the use of flood defenses: sustainable options have to be designed to better mitigate the effects of flooding in urban area and in a long term strategy. Several European cities have suffered recent flooding events. It was the case for example in 2007 in United Kingdom. During this period, major events came from extreme rainfall and it appears that pluvial flood risk has become one of the most frequent events. In this context, flood risk can appear on every territory: cities have to develop some methods to take into account this new deal, options to achieve urban flood resilience. Some solutions that cities are using or will be able to set up in the near future will be described.
\end{abstract}

Keywords: flood risk, resilience, urban environment.

\section{Introduction}

The coming years will be focused on solutions to solve the storage of oil: this means that sustainable cities have to find a way to cut their oil dependencies. In 
order to reduce the impact of climate change, dividing greenhouse gases by four has become a priority. Nowadays, a spatial organization of cities is advised: designing denser cities. This organization scheme is able to give a reasonable answer to tackle the energetic problematic and then to make sustainable cities. But, is this urban morphology pattern able to face natural risks? Indeed, this urban shape will increase issues exposed to hazards, like buildings and infrastructures, people, and also the economy of the considered territory. Furthermore, in France the flooding risk annual damage is equivalent to $80 \%$ of the cost due to natural risks. This annual cost is estimated at more or less 250 millions of Euros: $33 \%$ of the cities are concerned, about 300 conurbations.

At the same time, uncertainties due to hazard are still populated in forecasting models and are definitely increasing due to global change. How to measure this climate change without introducing new uncertainties coming on the one hand several scenarios design, on the other hand on extrapolation methods? Dealing with flood risk management it raises the question of the return period we have to consider to design flood defenses. Do we have to protect ourselves from the one hundred return period or the one thousand return period? How to decide in this uncertain world?

Finally, all these elements lead us to more global and complete methods to deal with flood risk management in cities, especially in integrating both climate change uncertainties and new urban morphology to design real sustainable cities. In this framework, the resilience concept has become central to bring some answers needed by urban areas:

- Denser cities gather issues and increase their vulnerability to flood. Does post carbon urban shape contribute to reduce urban flood risk?

- How could the resilience concept help to propose some methods and tools to design cities able to avoid flooding or able to be flooded without damages?

- Can we qualify cities as sustainable if they are not resilient?

This paper describes in a first part the society flood risk evolution and issues that resilience has to take into account to participate to urban sustainability production. In a second part we will present the kind of structural measures to protect cities against flood events. At least, a third part will be dedicated to nonstructural measures and how it can complete flood protections defenses to reduce urban flood risks.

\section{Resilience and sustainable cities}

2007 has been a crucial year: half of the world population is living in urban areas. This growth will continue at an exponential speed: the number of inhabitants in cities will double during the next 30 years. This increased rate is equivalent to the creation a new city of 1 million of people every week [1]. This urban development speed up (Fig. 1) has a huge impact on the question of risk management.

Urban increase combined with climate change and all the uncertainties generated by this global change will induce situations at risk in the urban 


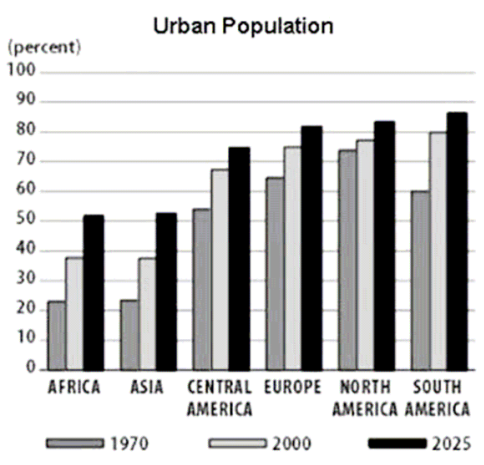

Figure 1: $\quad$ Growth of the urban population [2].

environment. Indeed, as a result of climate change and urban growth, densification and concentration, a severe increase of issues and vulnerability is expected. As an example, flood risk will have a significant increase: damage cost will achieve a value of 100 milliards of Euros, every year at the end of the century. About $75 \%$ of these damages will occur in urban areas [3]. To summarize, cities will suffer more frequent hazards and become more vulnerable: this lead to a situation where cities have to find solutions to be more resilient, to find solutions to be more adaptable to such events.

The origin or the resilient concept comes from physic science: this is the capacity of a material to recover its initial condition following a shock or pressure. This concept has also been used in other domains like psychology, ecology. In 1973 the resilience concept was introduced to analyze system resilience [4]. Dealing with flood risk management, resilience is considered as "the ability of a system/community/society/defence to react to and recover from the damaging effect of realized hazard" [5]. When we introduce this concept to analyze urban systems, it is defined as "the capacity of a city to face devastating event reducing damage at a minimum" [6]. Defining, assessing and designing urban resilience contributes in this framework to produce sustainable cities [7].

Resilience has become these last years the central core for sustainable risk management, especially in Anglo Saxon countries. For urban flood risk management, the goal is to find equilibrium between structural measures and non-structural measures able to tackle residual risk coming from dysfunctions of structural measures.

\section{Structural measures}

\subsection{Context}

To solve effects due to flood risk, populations have always tried to protect themselves. First in using high ground level to not be reached by river flooding: passive protection. Finally inhabitants have tried to control river flooding to live 
closer to rivers and to be able use their benefits like commercial exchange possibilities. That is the reason why cities are always located near rivers (or near the sea). This active protection has been possible by the step-by-step levee erection. Like the river Loire levee, the older levees still operating were built during the Middle Ages. Despite this kind of flood defenses, some flood occurred, and continue to occur now, due to levee failures.

In the world, flood frequency and intensity has increased this last decade. These events lead generally to levee failures: consequently this technological risk coupled with natural flooding increase damages in areas protected by flood defenses. We can cite several cases these last years:

- 1999, 2002 and 2003 flood events in the South of France;

- 1998 along the river Yangtze in China where levee failures caused the death of 2000 people according to the Chinese government;

- 1998 in Saint Louis (USA) along the Mississippi river where levee achieving a height of 15 meters collapsed;

- 2005, New Orleans (USA) where the canal levee failed during Katrina causing major flooding in the main parts of the city and killing 1464 people.

Levee diagnosis and maintenance [8] has become a central part of flood risk management because failures can cause massive damage in terms of victims and economic loss, as shown in Fig. 2.

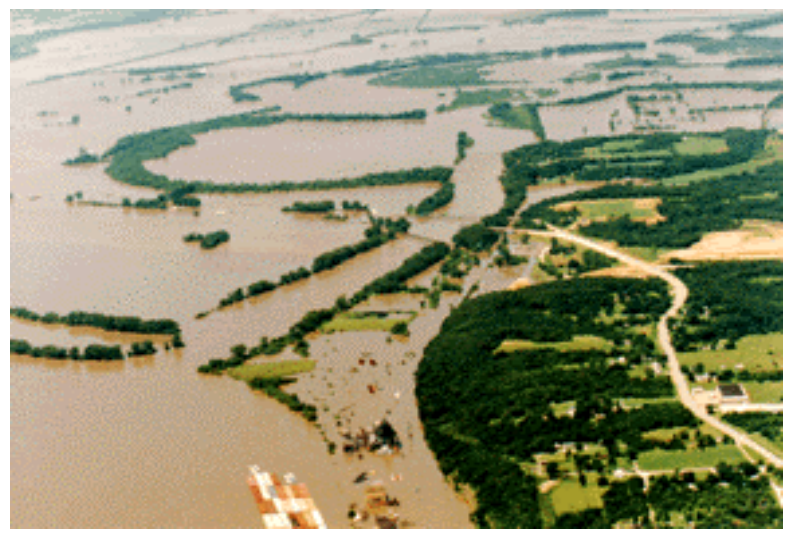

Figure 2: $\quad$ Floodings in Languedoc-Roussillon, 1999.

Despite this risk failure, flood defenses continue to be used and built because some cities do not have the possibility to be located where they are without flood defenses: this is particularly the case of New Orleans in the USA.

\subsection{New Orleans hurricane and storm damage risk reduction system}

New Orleans city has begun its urbanization using the city's natural high ground which suffered only minor flooding from Katrina and Rita. Like most of the cities, New Orleans growth leads to the authorization to build up the city in other areas, lower both than the Mississippi river and the Lake Pontchartrain (Fig. 3). 


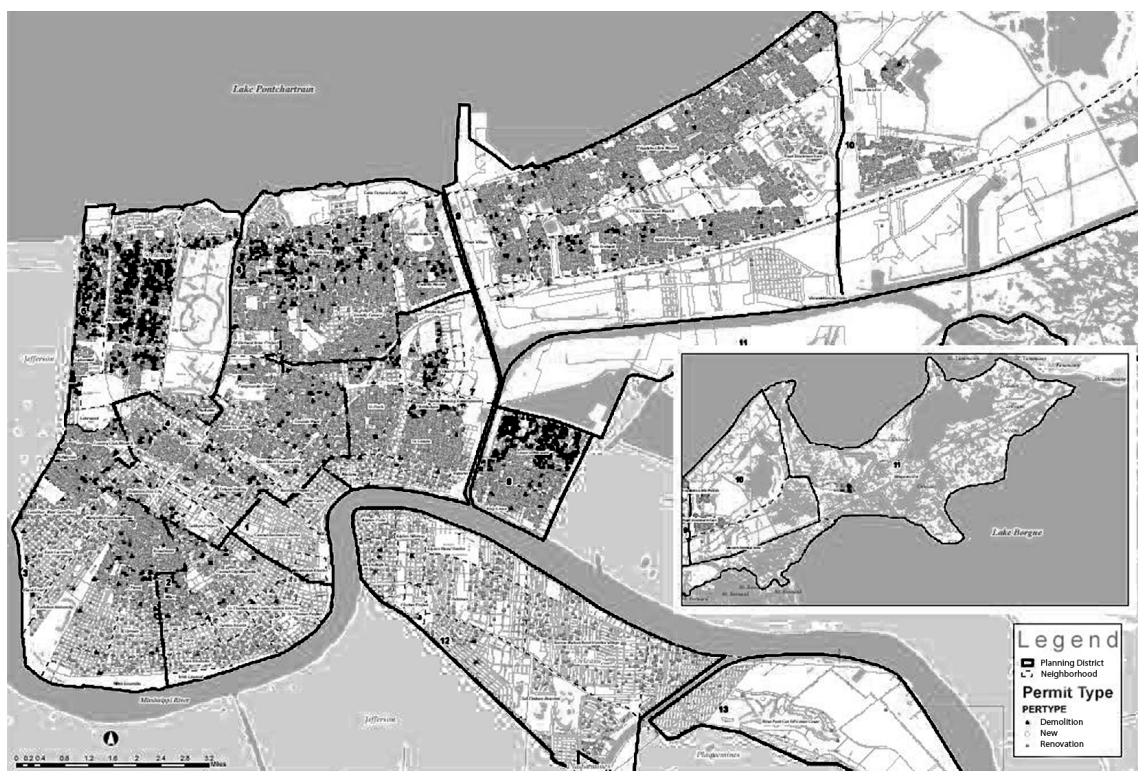

Figure 3: 2007 New Orleans land use.

This phenomenon induced the construction of a complex flood protection system to protect New Orleans from fluvial flooding, estuarial flooding but at the same time lake flooding, from Lake Pontchartrain (North) and Lake Borgne (East) (Fig. 4).

Due to its topography, the surname of the city is "the bowl" (Fig. 5).

Due to this specific topography, the city has to be permanently drained. This drainage function is fulfilled by several canals. These canal walls failed during Katrina, whereas the major flood protection system composed by the Mississippi levees and Lake Ponchartrain resisted. The city was flooded by the collapse of canal flood walls during 53 days, 2 meters deep in some parts.

New Orleans inhabitants were shocked by this failure because they were very confident about this flood protection system. Also, the population return was first conditioned by the rebuilding of the levees: not only the canal levees that failed, but the major part of these protections. So it was decided to heighten, reinforce, reshape all the flood protection system to be able to face a one hundred return period event (Fig. 6).

In one way all this levee system is vital for New Orleans: without it there was no reason to rebuild the city after Katrina. It constitutes a first step to New Orleans flood resilience, but it is not enough: the residual risk has to be taken into account. To achieve a resilient urban system, a water bottom-up approach should have been designed including urban planning, awareness, mitigation [9]. But the risk now is that the New Orleans authorities and inhabitants feel safe again behind levees and forget the next steps to a resilient and sustainable resilient city... 


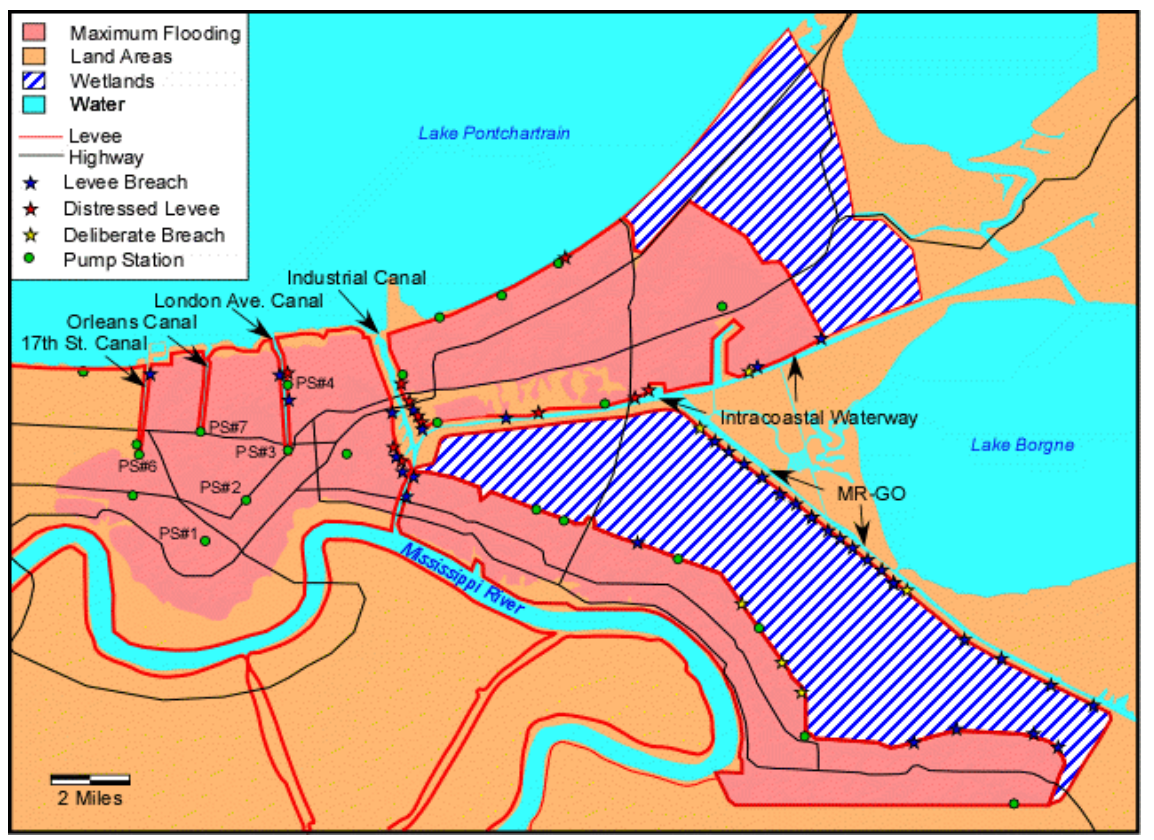

Figure 4: $\quad$ Flood protection system (Tulane University).

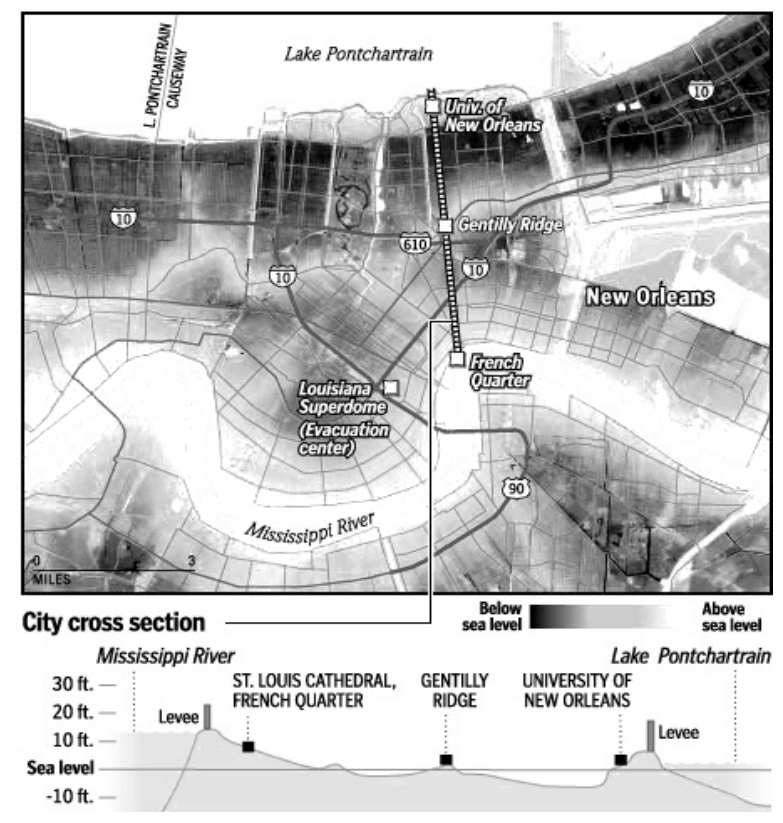

Figure 5: City of New Orleans ground elevation, the "bowl". 


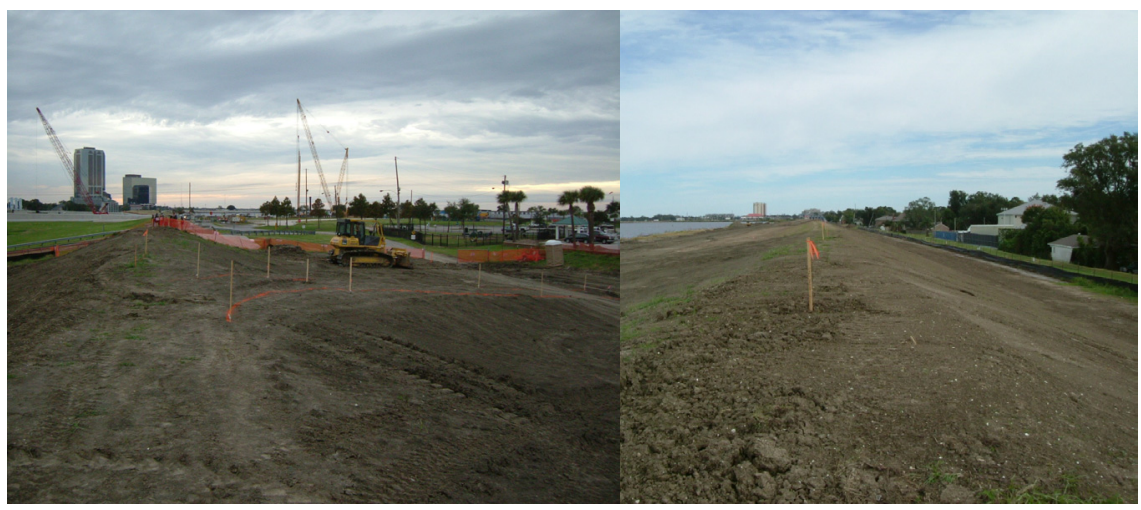

Figure 6: Levee construction and reinforcement.

\section{Non-structural measures}

\subsection{Context}

Even if research focused on hazard management are numerous and of course important for risk management, we realized that it is no more possible to control major events and there effects by hazard management only: a residual risk always exists and flood defenses are necessary but not enough to reduce risks. It has become necessary to accept the fact that a city is still able to suffer flooding during extreme or rare events. This means that resilient urban planning has to be set up to make cities able to reduce damages and to speed up its recover: urban resilience concept should be able to bring some simple and intelligent answers.

\subsection{Surface management of rainwater as a palliative for a rainwater network when under river flooding conditions}

The town centre of Villeneuve Saint Georges is located between a straight railway embankment (forming a slope similar to a dyke), and a hillside. Its drainage network is inadequate for offsetting the impact of urban planning and contains numerous non-conformities on connections with the separate sewerage networks. Furthermore, the experimental non-sloping waste water network collects water by gravity to direct it to a manhole called the "transfer well". Water is channeled from the manhole to the storage tank located in the waterworks by applying a pressure differential on the piping (Fig. 7).

Numerous dysfunctions have been observed on the network, giving rise to chronic flooding. Over and above network problems, flooding is due to a number of different factors, rainwater run-off due the topography of the area, transport infrastructure developments that have ignored risks by blocking natural outfalls through building the embankment, urban planning that has made a considerable part of the land impervious, numerous resurgences and diverted springs, etc. 
Rail road and

national road

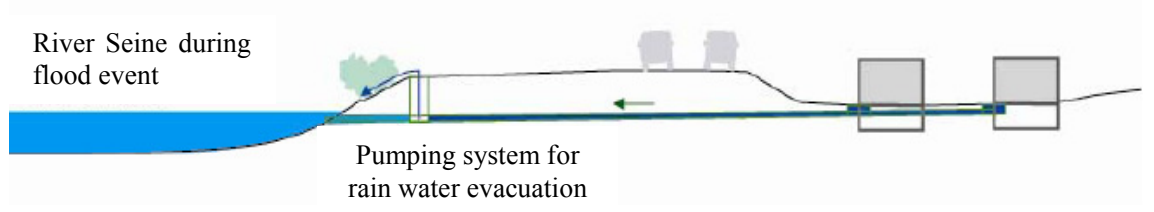

Figure 7: Flow diagram for evacuating rain water when the river Seine is in flood condition.

When the level of the Seine rises, installations prevent water welling up through the networks. Pumps have been installed for draining water from the network. These pumps play an essential role, but it is difficult to guarantee that they will all operate correctly throughout a long flood period. If the Ile-de-France area has to face up to 100 -year flood conditions on the river Seine, the water level will remain high for several weeks and it will most certainly be impossible to guarantee that the power supply to the pumps can be maintained.

Reclassifying the town centre of Villeneuve Saint Georges is a part of a sustainable approach to urban planning, which, in this case, means balanced dynamics, directed towards satisfying vital requirements, providing access to essential services, reducing insalubrities and increasing urban potential (Fig. 8).

If the proposal made by the Makan Rafatdjou architectural and urban planning agency and the Composante Urbaine design office has been retained, it is both for the urban quality of the global project and for the water management proposals. These proposals are incorporated into infrastructure modifications, urban morphology, construction designs and the modifications made to the existing system for controlling run-off water. Proposals comply with the Val de Marne Flood Risk Prevention Plan. Measures for the sector more especially concern adapting the town-centre to flooding. The solution proposes modifications in micro-topography offset by floodable car parks and measures taken in supporting structures that use the overpass for the RN6 for creating inlets and outfalls above maximum flood levels.

The water law of January 1992 stipulates that developments must offset their impact on rainwater run-off. In the context of reclassifying the town-centre, there is no increase in impervious surfaces on the land. However, in order to face up to the existing situation, designers propose a strategy that consists of managing rain-water by:

- Storing water in the town centre by reclassifying public land to offer a storage capacity of 1100 cubic meters, and in new blocks using various storage techniques especially in roofing. These blocks will also contain floodable constructed areas;

- Slowing rain water down and storing it as high upstream as possible by reclassifying neglected areas on the hillsides; 

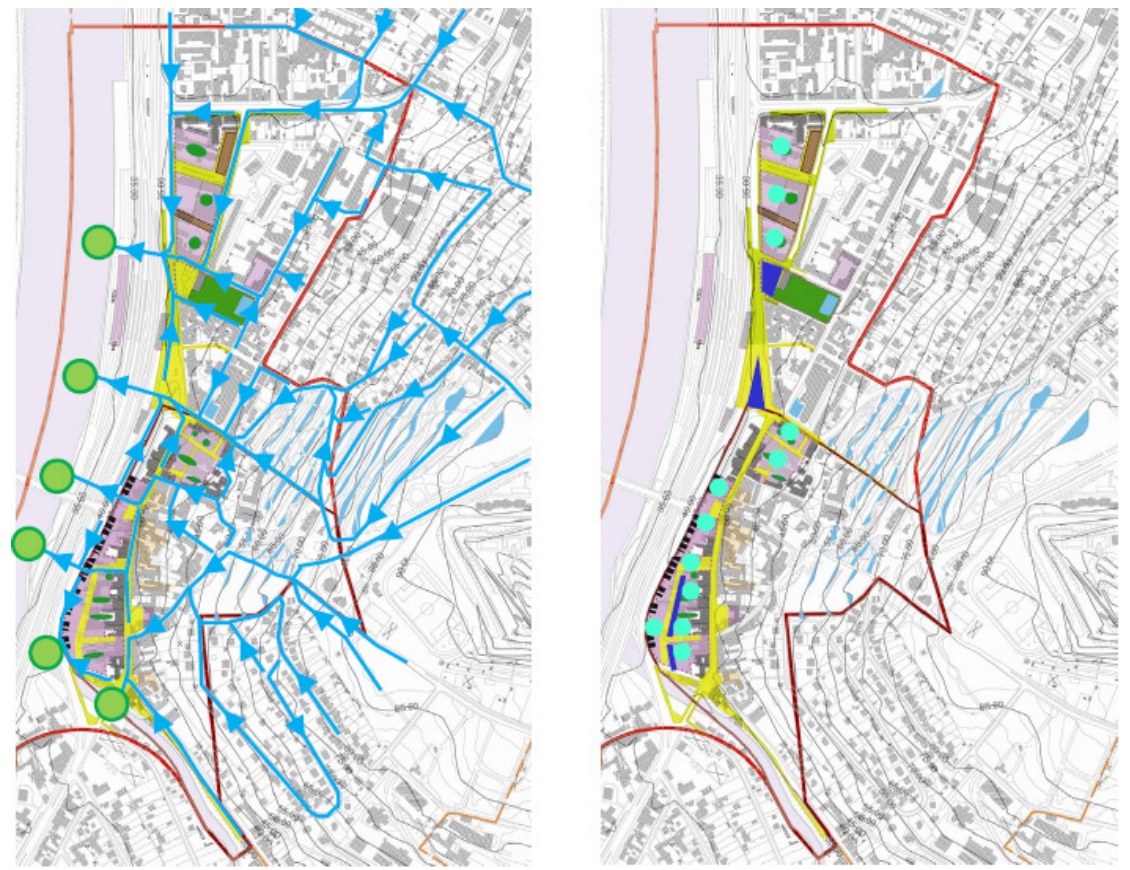

Figure 8: $\quad$ Surface water circulation after reorganization. New surface water management system (left picture), storage zone area design (right picture).

- Privileging surface run-off on public land in order to channel water away to storage areas.

\section{Conclusions}

City managers have to take into account a lot of issues to design sustainable cities, like:

- Climate change;

- Energy and carbon emission reductions;

- Risk management in a changing world;

- Economy with new issues.

Dealing with flood management, the cost of structural measure is becoming prohibitive to continue to manage flood risk in that way. A city like London wouldn't have been able to build up a new Thames barrier any more in this changing world. Also Shanghai, suffering already the consequences of sea level rise, is not able to be protected only by structural measures. 
That is the reason why, these last years, resilience has become a central concept for risk management. This concept has emerged because a more resilient system is less vulnerable to risk and, therefore, more sustainable. Generally resilience is using simple measure, sometimes forgotten measures that are quite simple to design and of course more cost effective than structural measures. Such non structural measures are also more environmental by giving more spaces for flood expansions.

EU FloodResilienCity project allows designing some solutions to design new resilient neighborhood and to adapt cities to better absorb flooding consequences. Sharing of 8 European cities and 6 nations knowledge contributes to very efficient international exchanges on that question.

\section{Acknowledgements}

The authors wish to express their thanks to the different designers of the Villeneuve-Saint-Georges projects - the Makan Rafatdjou architectural and urban planning agency (Paris), official representative/Composante Urbaine/Hélène Saudecerre/Polyprogramme/IDCités/Jean-Michel Viguier.

As well as the designers of the Saint-Ouen docks industrial area, the Makan Rafatdjou architectural and urban planning agency (Paris), official representative/the Bernard Reichen and Philippe Robert and Associates architectural and urban planning agency (Paris)/the Olga Tarrasso architectural and urban planning agency (Barcelona)/Hélène Saudecerre landscape architect/the Amador Ferrer architectural and urban planning agency (Barcelona) /Taoufik Souami Architect, Doctor in urban planning and sustainable development/Marc Desportes ENPC engineer, Doctor in urban planning together with all the contributions in environmental contracting assistance made by ReSources/Adage/Dac Communication and in specialist technical design by Yann Le Gal/Composante Urbaine/Bérim/Arcadis/CVL

Our thanks go more especially to Mr Makan Rafatdjou, who received us at length and provided the documents on these projects.

\section{References}

[1] www.floodresiliencegroup.org

[2] APFM, Urban Flood Risk Management - A Tool for Integrated Flood Management. Associated Programme on Flood Management (APFM), Technical Document No.11, version 1.0, 2008.

[3] Ashley R., Vassilopoulos A., Pasche E., Zevenbergen C., Advances in Urban Flood Management, COST22 conference, UNESCO, 2008.

[4] Holling. C.S., Resilience and stability of ecological systems, Annual Review of Ecology and Systematics, pp. 124-149, 1973.

[5] www.floodsite.net

[6] Campanella T.J., Urban Resilience and the Recovery of New Orleans, Journal of the American Planning Association, Numéro 72, vol. 2, 141 p, 2006. 
[7] Muller M., Adapting to climate change, water management for urban resilience. Environment and Urbanization, Vol. 19, No. 1, pp. 99-113, 2006.

[8] Serre, D., Peyras, L., Tourment, R., Diab, Y., Levee performance assessment: development of a GIS tool to support planning maintenance actions, Journal of Infrastructure System, ASCE, Vol. 14, Issue 3, pp. 201213, 2008.

[9] Carbonell A., Meffert D., Climate change and the resilience of New Orleans: the adaptation of deltaic urban form, a draft paper with support from the Lincoln Institute of Land Policy commissioned by the World Bank, 39p., 2009. 